Ethiopian Journal of Environmental Studies \& Management 8(1): 39 - 44, 2015.

ISSN:1998-0507

doi: http://dx.doi.org/10.4314/ejesm.v8i1.4

Submitted: September 30, 2014

Accepted: January 12, 2015

\title{
SELECTED INDIGENOUS WILD FRUITS INFLUENCE ON FEEDING BEHAVIOUR OF CAPTIVE OLIVE BABOONS (Papio anubis. Lesson, 1827)
}

${ }^{*}$ OGUNJOBI, J.A., ${ }^{1}$ INAH, E.I., ${ }^{2}$ OYELEKE, 0.0., ${ }^{3}$ IKEABBAH, C. ${ }^{4}$ and ADEOLA, A.J. ${ }^{4}$

${ }^{1}$ Dept of Biological Sciences, Ondo State University of Sci. and Tech, Okitipupa, Ondo State.

${ }^{2}$ Dept of Forestry and Wildlife, University of Calabar, Cross River State

${ }^{3}$ Dept of Ecotourism and Wildlife Mgt., Federal University of Technology, Akure, Ondo State

${ }^{4}$ Dept of Wildlife and Ecotourism, Federal College of Wildlife Mgt., New Bussa, Niger State

\begin{abstract}
Feeding behaviour of captive male olive baboons was studied in a 200 feeding trial using five selected indigenous fruits: Strychnos spinosa (SS), Nuclear latifolia (NL), Piliostigma thonningii (PT), Detarium macrocarpum (DM) and Adansonia digitata (AD), categorized into large, medium and small sizes with a view to foster this animal ex-situ conservation. The fruits were harvested fresh and served on the floor of the cages in-between morning and afternoon routine feeding. Data were collected on fruit choice to determine fruits preference; time spent to remove or break the fruits pericarp; and the position of the animal while eating. This study shows that fruits preference was significantly $(p<0.05)$ influenced. It followed the order: $D M>N L>P T>S S>A D$. Experimental Olive baboons picked small fruits ahead of others irrespective of their nutritional quality. Time spent to remove or break the fruits pericarp were significantly $(p<0.05)$ influenced. On eighty-nine occasions, captive Olive baboons preferred hanging on the cages walls while eaten. For sustainable conservation of this fauna species, more research on its feeding behaviour with respect to these fruits shape, weight and colour is encouraged.
\end{abstract}

Key Words: Olive baboons, Conservation, Feeding behaviour, Wild fruits

\section{Introducion}

Effective management of animals inside Zoological gardens and similar environment requires considerable knowledge of the interaction between them and their environment. One of the animal that is of global interests most especially in the area of medicine to test drug efficacy before human consumption is baboons (WilliamsBlangero et al., 1990). It is important to understand the behaviour of primates in zoos/controlled environments as a means of ensuring better welfare, and to document

*Corresponding Author: Ogunjobi, J.A.

Email: ogunjonson02@gmail.com information for zoo visitors. For many consumptive and non-consumptive benefits of primate to be achievable, conservation efforts needs to be more directed towards its ex-situ management. In in-situ and ex-situ conservation, food availability, quality and composition are inevitable. According to Chapman et al. (2003) feeding behaviour is a valuable tool in primate conservation. Tovar et al. (2005) submitted that food composition and the strategy of provisioning influence the physical and psychological fitness of an individual 
animal for captive breeding programmes. Jordano (2000) reported that fruit is a regular part of the diet of almost all diurnal primate species and frugivorous primates commonly consume fruits and seeds of different plant species (Poulsen et al., 2001). Fruit and the preference for a fruitbased diet is usually related to the high content of easily digestible macronutrients, such as nonstructural carbohydrates and lipids, and to low levels of indigestible fibers and antifeedants (Milton, 1987). Herrera (1992) made known that phylogenetic may determine fruit traits at least to some degree while the contribution of Jordano (1993) revealed that frugivores may exert selection pressures on fruit characteristics (Jordano 1993). Essential to an understanding of the ecology of any organism is knowledge of nutritional aspects of their diet, as adequate nutrition is critical for successful reproduction (Barboza et al., 2009). In this study, the selected indigenous fruits growing within guinea savannah, Nigeria were categorized into sizes, chemical analysis of fruits was carried out before observation and documentation of fruits preference study, time spent to remove or break the fruit's pericarp and the eating position of captive adult male Olive baboons.

\section{Objectives}

The broad objective of this study was to investigate response of captive male Olive baboons served selected indigenous wild fruits

\section{Specific objectives}

To categorized the selected wild fruits into sizes

To determine the chemical composition of the selected wild fruits

To evaluate fruits preference of captive male Olive baboons
To calculate time spent by captive male Olive baboons to remove fruits pericarp

To observe position of the experimental animals during eating

\section{Methodology}

This study was conducted at the minizoo of Federal College of Wildlife Management, New Bussa, Niger State, Nigeria. The college is located on latitude $7^{\circ} 08^{\prime}$ and $1^{\circ} 00^{\prime} \mathrm{N}$ and longitude $4^{\circ} 30^{\prime}$ and $4^{\circ} 33^{\prime} \mathrm{E}$ in-between Kainji dam and New Bussa, Niger State (Ogunjinmi et al., 2007). Preliminary observations of fruits regularly patronize or shadow by wild Olive baboons within the college estate was conducted. Experimental animals comprised of four differently caged adult male Olive baboons while the five experimental fruits items are Detarium macrocarpum, Nuclear latifolia, Adansonia digitata, Piliostigma thonnigii, and Strychnos spinosa. These fruits were collected fresh on daily bases within the College estate. We measured fruits length with a sliding calliper (accuracy $0.01 \mathrm{~mm}$ ), but used ruler for large and elongated fruit. The fruits were classified into small, medium and large following the procedure of Lambert and Garber (1998) while the chemical composition was conducted accordingly (AOAC, 1990). These experimental fruits were then served in a 200 feeding trial on the floor of the cages from $12 \mathrm{hrs}$ to about $14 \mathrm{hr}$, after the usual morning feeding and before the evening feeding. In order to counterbalance possible food position preferences by the experimental animals, the served fruits were pseudo-randomized. Fruit choice was monitored through visual observation of the first chosen fruit. Fruit preference was determined through modification in the formula outlined by Tomlinson (1980). Percentages obtained were ranked 
according to their order of magnitude from highest to lowest, thus providing a preference ranking. A stopwatch was used to record the time spent by these animals to remove or break the pericarp of fruits picked. The data generated were analyzed using descriptive statistics, student t-test and one-way analysis of variance. Significant differences between the means were determined using the LSD test.

\section{Results and Discussion}

The description and chemical composition of the experimental fruits are presented in Tables 1 and 2. It was revealed that the chemical composition of the fruits items are within the range informed by to support growth, reproduction and regulation of body functions in baboons (Richard, 1998; Akosin et al., 2010; Akinyemi and Kayode, 2013).

Table 1: Description of experimental fruits

\begin{tabular}{llll}
\hline Fruits & Mean Length $(\mathrm{cm})$ & Mean Diameter $(\mathrm{cm})$ & Size \\
\hline Detarium macrocarpum & $3.70 \pm 0.30$ & $3.18 \pm 0.47$ & Small \\
Nuclear latifolia & $6.30 \pm 0.12$ & $4.70 \pm 0.20$ & Small \\
Adansonia digitata & $12.10 \pm 0.10$ & $10.20 \pm 0.70$ & Big \\
Piliostigma thonningii & $10.70 \pm 0.69$ & $5.42 \pm 0.25$ & Medium \\
Strychnos spinosa & $7.60 \pm 0.20$ & $7.68 \pm 0.20$ & Big \\
\hline
\end{tabular}

Table 2: Chemical composition of the experimental fruits

\begin{tabular}{l|lllll|lllll}
\hline Items & \multicolumn{2}{|l}{ Proximate (\%) } & & & & \multicolumn{2}{l}{ Elements $(\mathrm{mg} / 100 \mathrm{~g})$} & & \\
& $\mathrm{DM}$ & $\mathrm{CP}$ & $\mathrm{CF}$ & $\mathrm{Ash}$ & $\mathrm{EE}$ & $\mathrm{K}$ & $\mathrm{Mg}$ & $\mathrm{Ca}$ & $\mathrm{Fe}$ & $\mathrm{Zn}$ \\
\hline D. macrocarpum & 89.20 & 7.58 & 10.20 & 4.12 & 4.50 & 99.20 & 75.85 & 70.40 & 30.20 & 5.30 \\
N. latifolia & 32.10 & 10.20 & 14.48 & 5.34 & 4.90 & 105.19 & 70.10 & 76.00 & 30.05 & 5.20 \\
A. digitata & 90.00 & 18.80 & 16.10 & 5.70 & 3.20 & 241.10 & 21.10 & 17.00 & 6.00 & 1.75 \\
P. thonningii & 70.15 & 9.80 & 30.60 & 6.40 & 3.10 & 35.73 & 14.10 & 86.04 & 3.70 & 0.20 \\
S. spinosa & 72.25. & 5.45 & 2.60 & 17.20 & 10.45 & 37.60 & 11.00 & 70.20 & 3.10 & 0.90 \\
\hline
\end{tabular}

The result of fruits preference of captive Olive baboons in this study is presented in Table 3. Fruits preference followed the order Detarium macrocarpum $>$ Nuclear latifolia, > Piliostigma thonningii, > Strychnos spinosa $>$ Adansonia digitata. This preference may be as a result of the variation in fruit traits which include morphological fruit characteristics (e.g fruit colour, and the size), chemical and nutrient content of fruit and seeds reported (Russo, 2003). The order of preference in this study however differs from what was reported on wild Olive baboon (Akosin et al., 2010). Statistically, the differences observed in fruits preference of these indigenous five fruits served to the captive Olive baboons differs $(p<0.05)$ significantly (Table 4). This is probably due to hedonic pleasantness of the food's taste, smell, appearance, and texture reported (Rolls et al., 1981). The variation may also be connected with the study environment and food availability reported by Wansink (2004). Selected wild fruits preference ranking revealed that small sized fruits were most preferred. This partially agreed with the observation of Lambert and Garber (1988) where they reported that vast majority of fruit species in baboon diet was medium or large-sized. This study confirms earlier report by Silk, (1987) that other factors contribute to fruit choice. Fruit colour was also informed to enhance 
conspicuousness of fruits and detection by frugivores and advertise far-ranging information on fruit maturity (Schaefer $e t$ al. 2004).

Table 3: Fruit preference by captive Olive Baboons

\begin{tabular}{lccc}
\hline Served fruits & Frequency & Percentage & Preference Ranking \\
\hline Strychnos spinosa & 38 & 19.00 & $4^{\text {th }}$ \\
Nuclear latifolia & 41 & 20.50 & $2^{\text {nd }}$ \\
Piliostigma thonningii & 40 & 20.00 & $3^{\text {rd }}$ \\
Detarium macrocarpum & 61 & 30.50 & $1^{\text {st }}$ \\
Adansonia digitata & 20 & 10.00 & $5^{\text {th }}$ \\
\hline Total & 200 & 100 & \\
\hline
\end{tabular}

Table 4: Effects of fruit types on Fruit preference by captive Olive Baboons

\begin{tabular}{lllllll}
\hline \multicolumn{2}{l}{ Sources of Variation } & SS & df & MS & F & Sig \\
\multirow{2}{*}{ Fruits choice } & Between Groups & 16.614 & 4 & 4.154 & \multirow{2}{*}{3.470} & 0.009 \\
& Within Groups & 233.386 & 195 & 1.197 & & \\
\hline & Total & 250.000 & 199 & & &
\end{tabular}

Significant difference $(\mathrm{p}<0.05)$ exist in the fruits preference of these captive Olive baboons

The finding on time spent by the experimental animal to remove or break the pericarp of the served fruits is presented in Table 5. The highest time spent to remove the pericarp of higher proportion of Nuclear latifolia and Detarium macrocarpum chosen by the experimental olive baboon was between $30-49$ seconds. Majority of the pericarp of Piliostigma thonningii had the least time spent for their removal (10 29 seconds) while the pericarp of majority of Adansonia digitata and Strychnos spinosa fruits were removed between 50 69 seconds. Our findings on time spent by the animal to remove or break the pericarp differs $(\mathrm{p}<0.05)$ significantly (Table 6$)$. The trend in this finding may be connected with different pericarp texture of the experimental fruits. Lesser time spent to remove or broken the pericarp of Piliostigma thonningii fruits may be as a result of its size, texture and the ability of the experimental olive baboon to quickly handle this fruit.

Table 5: Time spent by captive Olive baboons to remove fruits pericarp

\begin{tabular}{|c|c|c|c|c|c|}
\hline $\begin{array}{lll}\text { Seconds }) & \text { Time } & \text { spent } \\
\text { Fruits items } & & \\
\end{array}$ & $10-29$ & $30-49$ & $50-69$ & 70 above & Total \\
\hline Strychnos spinosa & 07 & 14 & 17 & - & 38 \\
\hline Nuclear latifolia & 01 & 24 & 15 & 01 & 41 \\
\hline Piliostigma thonningii & 19 & 11 & 09 & 01 & 40 \\
\hline Detarium macrocarpum & 10 & 30 & 20 & 01 & 61 \\
\hline Adansonia digitata & 04 & 05 & 11 & - & 20 \\
\hline Total & 41 & 84 & 72 & 03 & 200 \\
\hline
\end{tabular}


Table 6: Analysis of Variance on fruits types against time spent

\begin{tabular}{|c|c|c|c|c|c|c|}
\hline \multicolumn{2}{|c|}{ Sources of Variation } & SS & df & MS & $\mathrm{F}$ & Sig \\
\hline \multirow{3}{*}{ Time spent } & Between Groups & 64.240 & 3 & 21.413 & 27.594 & 0.000 \\
\hline & Within Groups & 185.760 & 196 & 0.948 & & \\
\hline & Total & 250.000 & 199 & & & \\
\hline
\end{tabular}

There exists significant difference $(\mathrm{p}<0.05)$ in the time spent to remove fruits pericarp

The result of the finding on observation on eating position of the experimental Olive baboons is presented in Table 7. It was revealed that $89(44.5 \%)$ hanging on cages wall followed by those sitting $72(36 \%)$, standing 21(10.5\%) while the least $18(9 \%)$ was observed when the animals were moving. Different eating position is probably due to the temperament of the experimental animal and the presence of the researchers and visitors reported by CoussiKorbel and Fragaszy (1995). From this study, it is observed that fruits types, fruits sizes and fruit pericarp texture go some way to explaining feeding behaviour in captive Olive baboons. We suggest further study on the aspects of fruits colour, shape, size and pericarp texture on captive Olive baboon feeding behaviour.

Table 7: Eating position of the experimental Olive baboons

\begin{tabular}{l|l|l}
\hline Eating position & Frequency & Percentage \\
\hline Hanging of the cages wall & 89 & 44.5 \\
Sitting & 72 & 36.0 \\
Standing & 21 & 10.5 \\
Moving & 18 & 9.0 \\
\hline Total & 200 & 100 \\
\hline
\end{tabular}

\section{References}

A .O. A. C. (1990). Association of Official Analytical Chemists Official method of Analysis, Washington D. C.

Akinyemi, A.F and Kayode, I.B. (2013). Nutritional composition of plant materials consumed by Baboon (Papio anubis) and Tantalus Monkeys (Chlorocebus tantalus) in Yankari Game Reserve, Nigeria. J. Primatol 1(3): 1-5

Akosim, C., Joseph J. and Egwumah, P.O. (2010). Assessment of feeding behaviour of baboons (Papio anubis) in Hong hills Adamawa State, Nigeria. Journal of Research in Forestry, Wildlife and Environment. 2(1):60 -72.
Barboza, P.S., Parker, K.L. and Hume, I.D. (2009). Integrative Wildlife Nutrition. Springer-Verlag, Heidelberg.

Chapman, C.A., Chapman, L.J., Rode, K.D, Hauck, E.M. and McDowell LR. (2003). Variation in the nutritional value of Primate Foods: Among trees, time periods and areas. Int. J. Primatol 24: 317-333

Coussi-Korbel, S. and Fragaszy, D.M. (1995). On the relation between social dynamics and social learning. Animal Behaviour, 50: 1441-1453.

Herrera, C.M. (1992). Historical effectsa nd sorting processes as explanations for contemporary ecological patterns: character syndromes in 
Mediterranean woody plants. Am. Nat. 140:421-446.

Jordano, P. (1993). Geographical ecology and variation ofplant-seed disperser interactions:southern Spanish junipers and frugivorous thrushes. Vegetation 107/108:85-104.

Jordano, P. (2000). Fruits and frugivory. In Fenner, M. (ed.). Seeds. The ecology of regeneration in plant communities. CABI, Wallingford. Pp. 125-165

Lambert, J.E and Garber, P.A. (1998). Evolutionary and ecological implications of primate seed dispersal. American Journal of Primatology 45: 9-28.

Milton, K. (1987). Primate diets and gut morphology: implications for hominid evolution. In: Harris M, Ross EB, editors. Food and evolution: Toward a theory of human food habits. Philadelphia: Temple University Press. p 93-115.

Ogunjinmi, A.A., Meduna, A.J., Ajani, M. O., Osunsina, I.O.O. and Ogunjobi, J.A (2007). Preliminary observations on the rearing of crocodiles in captivity at Federal College of Wildlife Management, New Bussa. Niger State, Nigeria. Trop. J. Anim. Sci., 10(1-2): 129-133.

Poulsen, J.R., Clark, C.J. and Smith, T.B (2001). Seed dispersal by a diurnal primate community in the $\mathrm{Dja}$ Reserve, Cameroon. Journal of Tropical Ecology 17: 787-808.

Richard, A.F (1999) Primates in nature. W.H. Freeman and Company New York.

Rolls, B.J., Rowe, E.A., Rolls, E.T., Kingston, B., Megson, A. and
Gunary, R. (1981). Variety in a meal enhances food intake in man. Physiology \& Behavior, 26(2): 215221

Russo S. E. (2003). Responses of dispersal agents to tree and fruit traits in Virola calophylla (Myristicaceae): implications for selection. Oecologia 136: 80-87.

Schaefer, H.M., Schaefer, V. and Levey, D.J. (2004). How plant-animal interactions signal new insights in communication. Trends in Ecology \& Evolution 19: 577-584.

Silk, J.B. (1987). Activities and feeding behaviour of free ranging pregnant Baboons. Int. J. Primatology, 8(6): 593-613.

Tomlinson, D.N.S. (1980) Seasonal food selection by water buck Kobus ellipsiprymnus in a Rhodesian Game Park. South Afr. J. Wildl. Res. 1980 10(1).

Tovar, T.C., Moore, D. and Dierenfeld, E. (2005). Preference among four species of local browse offered to Colobus guereza kikuyuensis at the Central Park Zoo. Biology, 24:267274.

Wansink, B. (2004). Environmental factors that increase the food intake and consumption volume of unknowing consumers. Annual Review of Nutrition, 24: 455-79.

Williams-Blangero, S, Vandenberg, J, Blangero J, Konigsberg L and Dyke B. (1990). Genetic differentiation between baboon subspecies: Relevance for biomedical research. American Journal of Primatology, 20: 67-81. 